\title{
Large dependency of charge distribution in a tropical cyclone inner core upon aerosol number concentration
}

\author{
Yousuke Sato $^{1,2^{*}}$ (D), Yoshiaki Miyamoto ${ }^{2,3}$ and Hirofumi Tomita ${ }^{2,4}$
}

\begin{abstract}
The impacts of aerosols on the charge distribution of hydrometeors and lightning flash density in a tropical cyclone (TC) were investigated using a meteorological model coupled with an explicit lightning model. The meteorological model successfully simulated the tripole structure of charge density distribution in a TC, as reported by previous studies. The impacts of aerosols were investigated through a sensitivity experiment with changing the aerosol number concentration. The tripole structure became unclear with increasing aerosol number concentrations. The positive charge distribution located in the lower layer was not seen, and raindrops with negative charge distribution reached the surface. As a result, the vertical structure of the charge density was dipolar in the polluted case. As the tripole structure shifted to dipole, the magnitude of the electric field tended to be large, and the flash number was large. By contrast, in the pristine case, the tripole structure was dominant, and the flash number was much smaller than in the polluted case.
\end{abstract}

Keywords: Lightning, Tropical cyclone, Aerosol

\section{Introduction}

Aerosols, tiny particles in the atmosphere emitted from various sources such as forest fires, sea spray, agricultural waste, and industrial pollution, affect the microphysical properties of clouds by serving as the nuclei for cloud particles in a process called aerosol-cloud interaction (ACI; Twomey 1977; Albrecht 1989). As a result of ACI, the size of cloud particles decreases with the increasing number of aerosols, and the cloud albedo is increased (Twomey 1977). As well as the large cloud albedo, the rain formation is suppressed (Albrecht 1989) with increasing aerosols. Due to the suppression of rain formation, the timing of the precipitation and the precipitation amount are also changed with increasing aerosols. These interesting features have motivated a large number of scientists to investigate the ACI.

The impact of ACI on convective clouds and cloud systems has been investigated by several observational

\footnotetext{
* Correspondence: yousuke.sato@sci.hokudai.ac.jp

'Department of Earth and Planetary Sciences, Faculty of Science, Hokkaido

University, Kita 10, Nishi 8, Kita-ku, Sapporo, Hokkaido 060-0810, Japan

${ }^{2}$ Computational Climate Science Research Team, RIKEN Center for

Computational Science, 7-1-26 Minatojima-Minami-machi, Chuo-ku, Kobe,

Hyogo 650-0047, Japan

Full list of author information is available at the end of the article
}

studies (e.g., Sherwood 2002; Lindsey and Fromm 2008; Jiang et al. 2009). They reported that a greater number of small ice particles are observed near the top of convective clouds when the aerosol number is large.

In addition to observations, numerical simulations have also been used to interpret observational results and understand the effects of ACI. During the last three decades, a number of studies have investigated the impacts of ACI on convective clouds and cloud systems (e.g., Khain and Sednev 1995; Takahashi and Kawano 1998; Khain et al. 2001; Takahashi and Shimura 2004; Tao et al. 2007; Khain et al. 2008b; Iguchi et al. 2008; Tao et al. 2012). Based on these previous studies, Rosenfeld et al. (2008) suggested that convective clouds can be invigorated according to the increase in aerosol number concentration.

These studies on the effects of aerosols on convective clouds have expanded the interests of scientists to include the effects of aerosols on cloud systems, for example, tropical cyclones (TCs). Rosenfeld et al. (2007) and Cotton et al. (2007) investigated the effects of aerosol on TCs using numerical simulations and reported that the intensity of TCs is reduced with increasing aerosols, as reviewed in Rosenfeld et al. (2012). Based on their report, the reason for the reduction in TC intensity 
is the modulation of the pressure gradient between the center and outer rain band region of $\mathrm{TC}$ as a consequence of suppressing precipitation via $\mathrm{ACI}$ over the outer rain band region. In addition to $\mathrm{TC}$ intensity, Khain et al. (2008a) suggested the effect of aerosols on lightning activity in TCs through their two-dimensional spectral bin microphysical model nested from a threedimensional meteorological model. They reported that collisions between graupels and ice crystals tend to occur frequently in clouds generated under conditions of high aerosol number concentration. The frequent collisions between graupels and ice crystals result in frequent charge separation and lightning. However, they did not consider the charge density of hydrometeors, even though lightning occurs to neutralize the charge density. Instead, they identified the lightning activity using upward velocity, total ice content, and cloud water content, which made it difficult to discuss the effect of aerosols on the charge density in TCs.

Numerical simulation based on a meteorological model with an explicit lightning model (hereafter lightning model; e.g., Takahashi 1984; MacGorman et al. 2001; Mansell et al. 2005; Hayashi 2006) is a powerful tool for investigating the impact of aerosols on the charge density and lightning activity in cloud systems. In the lightning model, the charge density of hydrometeors is explicitly predicted, and the impacts of aerosols on the charge density and lightning can be investigated explicitly. Shi et al. (2015) investigated the impact of aerosols on the lightning frequency of isolated convective clouds by two-dimensional model. Mansell and Ziegler (2013) investigated the impact of aerosols on the lightning accompanying a squall line using a meteorological model. However, it was difficult to conduct numerical simulations coupled with the lightening model that covered the entire area of the TC due to the large computational costs. Recent advances in computational power enable us to conduct numerical simulations of TCs coupled with a lightning model (e.g., Fierro et al. 2007; Fierro et al. 2013; Fierro et al. 2015). Fierro and Mansell (2017 and 2018) reported that lightning is more active in the outer rain band than in the inner core region, which supports the previous observational studies (e.g., Molinari et al. 1999; Cecil and Zipser 2002; Cecil et al. 2002; Abarca et al. 2011). They also reported that the vertical structure of the charge density is a tripole (i.e., positive to negative to positive from cloud bottom to cloud top). However, the series of numerical simulations of TCs with a lightning model have not yet investigated the effect of aerosols on the vertical structure of the charge density and the lightning frequency in TCs.

TCs form over the tropical ocean, where the aerosol number concentration is small, and move to midlatitude region with large amount of aerosol during their lifecycle. This implies that TC is affected by the aerosol during their lifecycle. The recent observational studies indicated the relationship between the lightning frequency and the lifecycle of TCs (e.g., Price et al. 2009; DeMaria et al. 2012). Some of them imply that the lightning frequency can be used as an index of the prediction of the TC's intensity (Price et al. 2009). However, these studies did not discuss the effect of aerosols on the lightning frequency. Thus, it is required to investigate the impact of the aerosol on the lightning, if the lightning is used for the index of the prediction.

We aimed to investigate the effect of aerosols on the vertical structure of charge density and lightning frequency in a TC using a meteorological model coupled with a lightning model. To achieve this goal, we developed a new lightning model based on previous studies and implemented it in a meteorological model. Numerical simulations were conducted with different aerosol number concentrations, and the results were analyzed to reveal the effect of aerosols.

\section{Methods \\ Model description and development of the lightning model}

The meteorological model used in this study was the Scalable Computing for Advanced Library and Environment (SCALE; Nishizawa et al. 2015; Sato et al. 2015) library version 5.0.0 We developed a new lightning model and implemented it in SCALE in this study.

The prognostic variables for the lightning model were charge densities of hydrometeors, as in previous studies (Takahashi 1978; Mansell et al. 2005; Barthe et al. 2005; Barthe et al. 2012; Fierro et al. 2013). The charge density was treated as a tracer. The lightning model was adopted for all microphysical schemes in SCALE, which is a unique feature of the lightning model implemented in SCALE. The hydrometeors were expressed by the various methods in SCALE according to the cloud microphysical schemes. SCALE has three types of microphysical schemes that consider ice particles: a one-moment bulk scheme (Tomita 2008), a two-moment bulk scheme (Seiki and Nakajima 2014), and a one-moment spectral bin scheme (Suzuki et al. 2010). The former two schemes predict hydrometeors based on five categories (cloud, rain, ice, snow, and graupel), while the third scheme predicts the size distribution function (SDF) of seven categories of hydrometeors (cloud, plate-like ice, columnar ice, dendrite ice, snow, graupel, and hail). The charge density of each of the five categories is predicted in the former two schemes, while that of each size category is predicted in the third scheme.

The lightning model is composed of three procedures: charge separation, calculation of the electric field $(\boldsymbol{E})$, and neutralization (discharge) of charge density. For the 
charge separation, we considered non-inductive charge separation, which is assumed to occur with the rebound of snow/ice particles after the collision with graupel particles, as in previous modeling studies (Takahashi 1978; Mansell et al. 2005). In addition to non-inductive charge separation, inductive charge separation (Ziegler et al. 1991) is often considered by other models. However, inductive charge separation was ignored in this study, because the contribution of inductive charge separation to the total charge density is much smaller than that of non-inductive charge separation (Mansell et al. 2005; Mansell et al. 2010).

The charge density of graupel $\left(\rho_{e, g}\right)$ and ice/snow $\left(\rho_{e, i}\right.$, $\left.\rho_{e, s}\right)$ obtained by the rebound after the collision in each time step was calculated based on the stochastic coalescence equation (cf. Pruppacher and Klett 2010) in the three microphysical schemes as:

$$
\begin{aligned}
\frac{d \rho_{e, g}}{d t}= & \beta \delta \rho^{\prime} \int_{0}^{\infty} \int_{0}^{r_{2}} n_{g}\left(r_{1}\right) n_{i, s}\left(r_{2}\right) \pi\left(r_{1}+r_{2}\right) \\
& \times\left|V_{g}\left(r_{1}\right)-V_{i, s}\left(r_{1}\right)\right| E_{\text {coll }}\left(1-E_{\text {coal }}\right) d r_{1} d r_{2}, \\
\frac{d \rho_{e, i / s}}{d t}= & -\frac{d \rho_{e, g}}{d t}
\end{aligned}
$$

where $r_{1}, r_{2}, n_{g}, n_{i, s}, V_{g}, V_{i, s}, E_{c o l l}$, and $E_{\text {coal }}$ are the radius of graupel, radius of ice/snow, number concentration of graupel, number concentration of ice/snow, terminal velocity of graupel, terminal velocity of ice/snow, collision efficiency, and coalescence efficiency, respectively. $\delta \rho$, defined as:

$$
\delta \rho^{\prime}=\alpha \delta \rho,
$$

is the charge density separated by one collision and rebound, and $\alpha$ is given as

$$
\alpha=5.0\left(r_{2} / r_{0}\right)^{2} V_{g} / V_{0},
$$

based on Takahashi (1984), where $V_{g}$ is graupel terminal velocity, and $V_{O}$ and $r_{O}$ are $8 \mathrm{~m} \mathrm{~s}^{-1}$ and $50 \mu \mathrm{m}$, respectively. $\delta \rho$ is obtained from a look-up table (LUT) from Takahashi (1978), as shown in Fig. $1 . \beta$ is $1,1-[(T+$ $30) / 13]^{2}$, and 0 for temperature $(T)$ warmer than $-30^{\circ} \mathrm{C}$, between -43 and $-30{ }^{\circ} \mathrm{C}$, and colder than $-43^{\circ} \mathrm{C}$, respectively, based on Mansell et al. (2005). To avoid an unrealistically large charge density, $\alpha$ is not permitted to be larger than 10, based on Takahashi (1984).

The electric field $(\boldsymbol{E})$ is calculated by solving the Poisson equation as:

$$
\begin{aligned}
& \nabla^{2} \phi=-\frac{\rho_{e}(x, y, z)}{\varepsilon}, \\
& \boldsymbol{E}=-\nabla \phi,
\end{aligned}
$$

where $\phi$ and $\varepsilon$ are electrical potential and atmospheric permittivity, respectively, and $\rho_{e}(x, y, z)$ is the charge density of each grid, which is the sum of the charge density of each hydrometeor in each grid. The calculation of Eq. (5) requires a large computational cost, as shown in Table 1, and a fast Poisson solver is necessary. In this study, the bi-conjugate gradient stabilized (BiCGSTAB) method (van der Vorst 1992), which was originally implemented in SCALE, was used to solve Eq. (5).

To calculate the charge neutralization, two schemes (MacGorman et al. 2001; Fierro et al. 2013) were implemented into SCALE. Both schemes neutralize the charge density when the electric field exceeds a threshold value $\left(E_{\text {int }}\right)$. The initial point of electric discharge is determined randomly among the grids in which $|\boldsymbol{E}|$ exceeds the $E_{\text {int }}$. By the scheme of MacGorman et al. (2001), the path of the lightning is explicitly calculated, and the discharge occurs along the path. By contrast, in the scheme of Fierro et al. (2013), the discharge occurs within vertical cylinders with a radius of $r_{\text {cylinder }}$ around the initial point. The details of both schemes are described in the literature.

\section{Experimental setup}

The experimental setup of this study targeted on an idealized TC, and it followed almost the same setup as a previous study targeting an idealized TC (Miyamoto and Takemi 2013), which was based on Rotunno and Emanuel (1987). The differences in this setup are the grid resolution, the lateral boundary, and the domain size. The calculation domain covered $3040 \times 2960 \mathrm{~km}^{2}$ with $5 \mathrm{~km}$ horizontal grid spacing and a doubly periodic lateral boundary. The number of vertical layers was 40 , and the layer thickness was gradually stretched from 200 to 1040

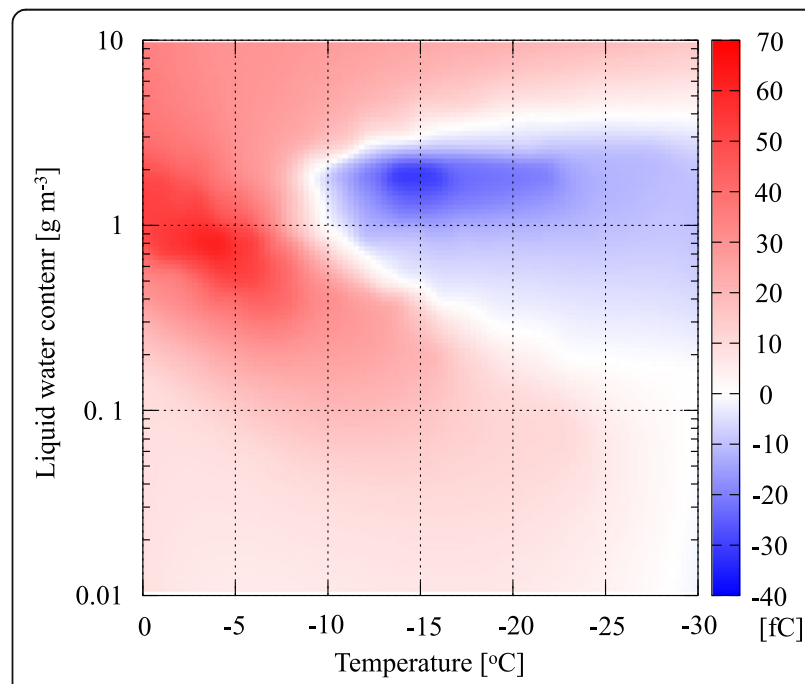

Fig. 1 Look-up table for the charge density of graupel with one collision, used for the charge separation process in SCALE. The data originated from Figure 8 of Takahashi (1978) 
Table 1 Summary of elapsed time. Elapsed time of each process related to the lightning model during calculation of the last $12 \mathrm{~h}$ in the control simulation

\begin{tabular}{lccc}
\hline Process & Calculation of the electrical field & Neutralization & Other cloud microphysics (including charge separation) \\
\hline Elapsed time $[\mathrm{s}]$ & 23,979 & 7.18 & 4768 \\
\hline
\end{tabular}

$\mathrm{m}$ at the model top $(21 \mathrm{~km})$. Rayleigh damping was adopted for $3 \mathrm{~km}$ from the model top. SCLAE has three microphysical schemes, the one-moment bulk, the twomoment bulk, and the spectral bin scheme. The twomoment bulk microphysical scheme (Seiki and Nakajima 2014) was used for this study. A Mellor-Yamada-type turbulence scheme (Nakanishi and Niino 2006) was used. The neutralization scheme of Fierro et al. (2013), where $E_{\text {int }}$ is $110 \mathrm{kV} \mathrm{m}^{-1}$ and $r_{\text {cylinder }}$ is $15 \mathrm{~km}$, was used in this study.

Horizontally homogeneous atmosphere with no wind, as shown in Fig. 2, was assumed for initial condition. To trigger TC's rotation, an axisymmetric vortex based on Rotunno and Emanuel (1987) was added at the center of calculation domain. The maximum wind speed of the vortex was $20 \mathrm{~m} \mathrm{~s}^{-1}$ with a radius of $120 \mathrm{~km}$, and the outermost radius of the vortex was $750 \mathrm{~km}$. The Coriolis force was added as the $f$-plane assumption with constant Coriolis parameter $f$ as $5 \times 10^{-5} \mathrm{~s}^{-1}$. The surface sensible and latent heat flux were calculated by a bulk scheme (Uno et al. 1995) assuming a constant sea surface temperature of $300 \mathrm{~K}$, and surface pressure was set as $1000 \mathrm{hPa}$. To save on the required computational resources, the calculation without the lightning model was conducted for $192 \mathrm{~h}$. During the $192 \mathrm{~h}$, the idealized TC achieved quasi-steady state. After $192 \mathrm{~h}$, calculations coupled with lightning model were conducted for $48 \mathrm{~h}$. Based on sensitivity experiments for the spin-up time, we only analyzed the results of the last $36 \mathrm{~h}$ to avoid artificial effects during spin-up.

To investigate the impact of aerosols on the charge density of the TC, we conducted sensitivity experiments for aerosols by running a parameter sweep of the aerosol number concentration. In the double-moment bulk scheme, the number concentration of cloud condensation nuclei $\left(\mathrm{CCN} ; N_{\mathrm{ccn}}\right)$ is predicted by the following equation (Twomey 1959):

$$
N_{\mathrm{ccn}}=N_{0} s^{k}
$$

where $s$ is the supersaturation with unit of \% diagnosed from prognostic variable of SCALE (specific humidity, total density, and potential temperature), $N_{0}$ is the number concentration of CCN when $s$ is $1 \%$, and $k(=0.462)$ is a constant. The $N_{0}$ was set as constant value during the whole time of the simulation, and it was changed as $10,50,100,500$, and $1000 \mathrm{~cm}^{-3}$ to investigate the effect of aerosol. Based on the literature (e.g., Table 9.1 of Pruppacher and Klett 2010), the range of $N_{0}$ over the ocean, where most TCs are generated, was from 25 to $400 \mathrm{~cm}^{-3}$. We henceforth called the simulation with $N_{0}=100 \mathrm{~cm}^{-3}$, which is the geometric mean of $25 \mathrm{~cm}^{-3}$ and $400 \mathrm{~cm}^{-3}$, the control simulation. $N_{0}=500 \mathrm{~cm}^{-3}$ and $1000 \mathrm{~cm}^{-3}$ correspond to polluted conditions over the continent, and $N_{0}=10 \mathrm{~cm}^{-3}$ and $50 \mathrm{~cm}^{-3}$ correspond to conditions over pristine ocean.
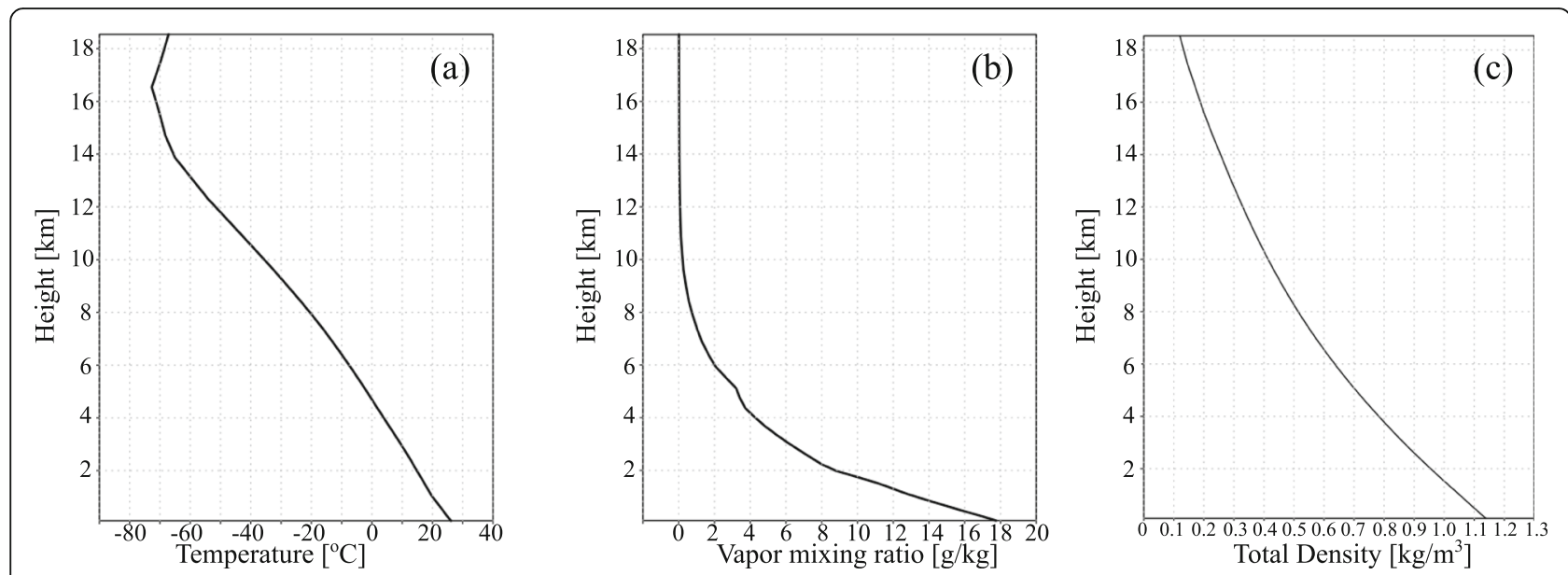

Fig. 2 The initial profiles of a temperature, $\mathbf{b}$ vapor mixing ratio, and $\mathbf{c}$ total density, which is defined as summation of density of air and vapor, used in this study 


\section{Results and discussion}

\section{Control simulation}

To validate the newly developed lightning model, we first checked the temporal evolution of maximum wind velocity, the vertical distribution of hydrometeors, and the charge density over the height $(z)$-radius $(R)$ plane.

Figure 3 shows the time series of the maximum wind velocity at the height of $1 \mathrm{~km}$ for the simulation without the lightning model (up to $192 \mathrm{~h}$ ). The maximum wind velocity remained at about $25 \mathrm{~m} \mathrm{~s}^{-1}$ until $60 \mathrm{~h}$ from the initial time of the simulation. It began to increase after $70 \mathrm{~h}$, then rapidly increased from time of 70 to $100 \mathrm{~h}$ (called rapid intensification; RI). After the RI, the maximum velocity gradually increased and reached steady state (after time of $160 \mathrm{~h}$ ). This temporal evolution was similar to that simulated by previous studies (Miyamoto and Takemi 2013), except that the maximum velocity at steady state was about $10 \mathrm{~m} \mathrm{~s}^{-1}$ weaker than that of the previous study. This weak velocity originated from the coarser grid spacing of this study $(5 \mathrm{~km})$ compared with that of the previous studies $(2 \mathrm{~km})$. Even though the maximum wind was weak, the basic characteristics of the TC lifecycle were reasonably reproduced.

The vertical structure of hydrometeors over the $z-R$ plane, averaged during the last $12 \mathrm{~h}$ of the simulation, is shown in Fig. 4a. Eyewall clouds, which are mainly composed of graupel, snow, ice, and liquid water (i.e., cloud droplets and raindrops), are clearly seen within $R$ smaller than $60 \mathrm{~km}$ and lower than $14 \mathrm{~km}$. Above the height of $14 \mathrm{~km}$, ice particles and snowflakes extend to the outer region $(R>60 \mathrm{~km})$ as anvil cloud. These characteristics are typically seen in the simulation of TCs (e.g., Franklin et al. 2005). The large mixing ratio of hydrometeors

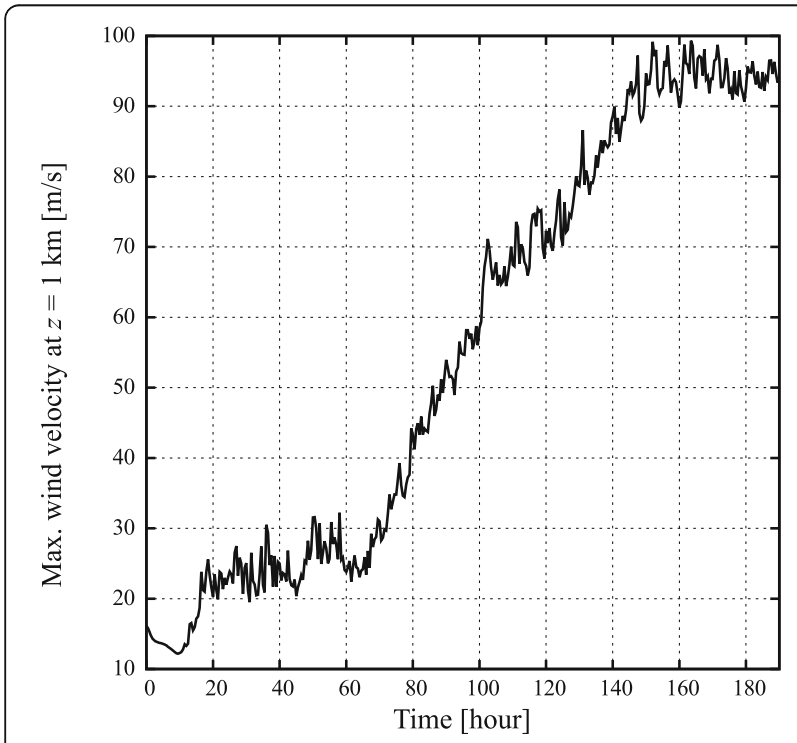

Fig. 3 Temporal evolution of maximum wind velocity at $z=1 \mathrm{~km}$
( $q_{\text {hyd }}:$ sum of the mixing ratio of the five categories, i.e., cloud, rain, ice, snow, and graupel) below $6 \mathrm{~km}$, where the temperature was warmer than $0{ }^{\circ} \mathrm{C}$, indicates that warm rain processes, which do not include frozen hydrometeors, are dominant in eyewall clouds, as reported by a previous study of a TC (Fierro and Mansell 2017). These results demonstrate that SCALE successfully reproduced the TC simulated by previous studies.

The vertical distribution of the charge density is shown in Fig. 4b. Near the center of the TC $(R<50 \mathrm{~km})$, the charge density varied from positive to negative to positive from the model bottom to top, which is quantitatively consistent with the reports of observational studies (e.g., Jacobson and Krider 1976; Krehbiel et al. 1979; Brook et al. 1982) and modeling studies targeting isolated convective clouds (MacGorman et al. 2001), squall line systems (Mansell et al. 2005; Mansell and Ziegler 2013), and TC (Fierro et al. 2007; Fierro et al. 2013). Thus, the structure of the charge density in TCs was reasonably reproduced by the lightning model implemented in SCALE.

The negative charge density between the height of 7 and $12 \mathrm{~km}$ is mainly composed of negatively charged graupel and snow/ice (dash-dotted green and orange lines, respectively, in Fig. 4b). The positive charge density within the height above $12 \mathrm{~km}$ originates from positively charged ice and snow particles (solid orange line in Fig. 4b). The positive charge density within the height below $7 \mathrm{~km}$ is composed of positively charged graupel and raindrops obtained from melting graupel (solid green and black lines in Fig. 4b).

To examine the reason for the polarity of graupel, snow, and ice at each height, the charge separation for each time step simulated in the model and temporal evolution of charge density over $z-R$ plane (Fig. 5) are useful. Around the height of $7 \mathrm{~km}$, the temperature is warmer than $-10{ }^{\circ} \mathrm{C}$. Under this condition, graupel is positively charged (Fig. 5a), and ice and snow are therefore negatively charged (Fig. 5b) based on the LUT shown in Fig. 1. Due to the positively charge separation for graupels, graupels are positively charged at this height during whole time of the simulation (Fig. 5d). The positively charged graupel falls down due to its greater density compared to ice and snow. The graupel and raindrops generated by melting graupel make up the positive charge density within the height below $7 \mathrm{~km}$ in the inner core region (solid black contour line in Figs. $4 \mathrm{~b}$ and $5 \mathrm{e})$. By contrast, the negatively charged snow and ice are carried upward by the upward velocity of the eyewall region and are distributed between the height of 6 and $11 \mathrm{~km}$ (Fig. 5c).

Around the height of $11 \mathrm{~km}$, in contrast to the height of $7 \mathrm{~km}$, graupel is negatively charged (Fig. 5a), and ice and snow are positively charged (Fig. 5b) because the 

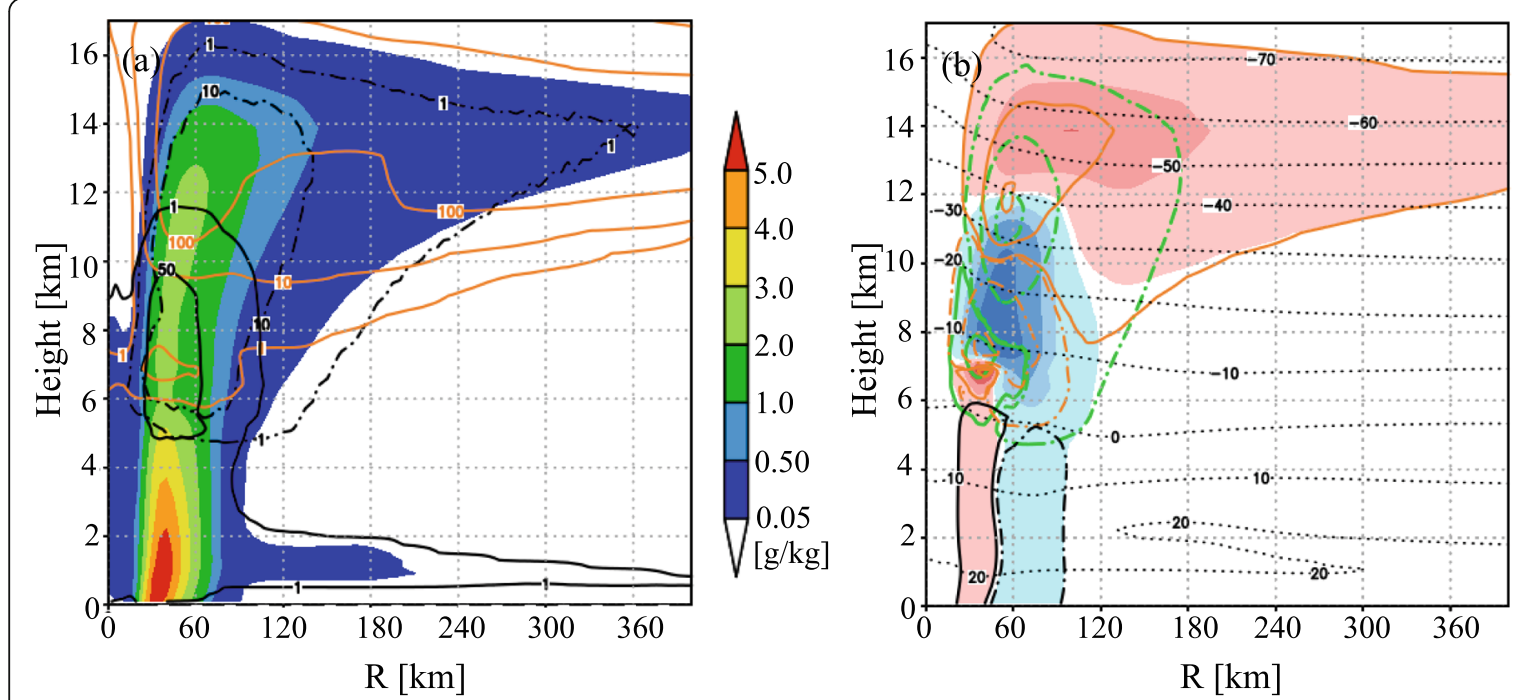

-0.3
0.2
0.1
0.05
0.01
-0.01
-0.05
-0.1
-0.2
-0.3
$\left[\mathrm{nC} / \mathrm{m}^{3}\right]$

Fig. 4 Number concentration of a sum of cloud water and rain water (black solid contour line), sum of ice and snow (orange contour line), graupel (black dot-dashed contour line), and total hydrometeor $q_{\text {hyd }}$ (shaded area); and $\mathbf{b}$ charge density of graupel (green contour line), sum of ice and snow (orange line), and cloud and rain (black contour line), and the total charge density over the $z-R$ plane (shaded area). The variables were tangentially averaged during the last $12 \mathrm{~h}$ of the simulation. Solid and dash-dotted contours in $\mathbf{b}$ show positive and negative charge densities, respectively, and contour lines in $\mathbf{a}$ and $\mathbf{b}$ show $0.05,1,3$, and $5 \mathrm{~g} \mathrm{~kg}^{-1}$ and $0.01,0.1$, and $0.3 \mathrm{nC} \mathrm{m}^{-3}$, respectively. The dotted line in $\mathbf{b}$ indicates temperature $\left({ }^{\circ} \mathrm{C}\right)$

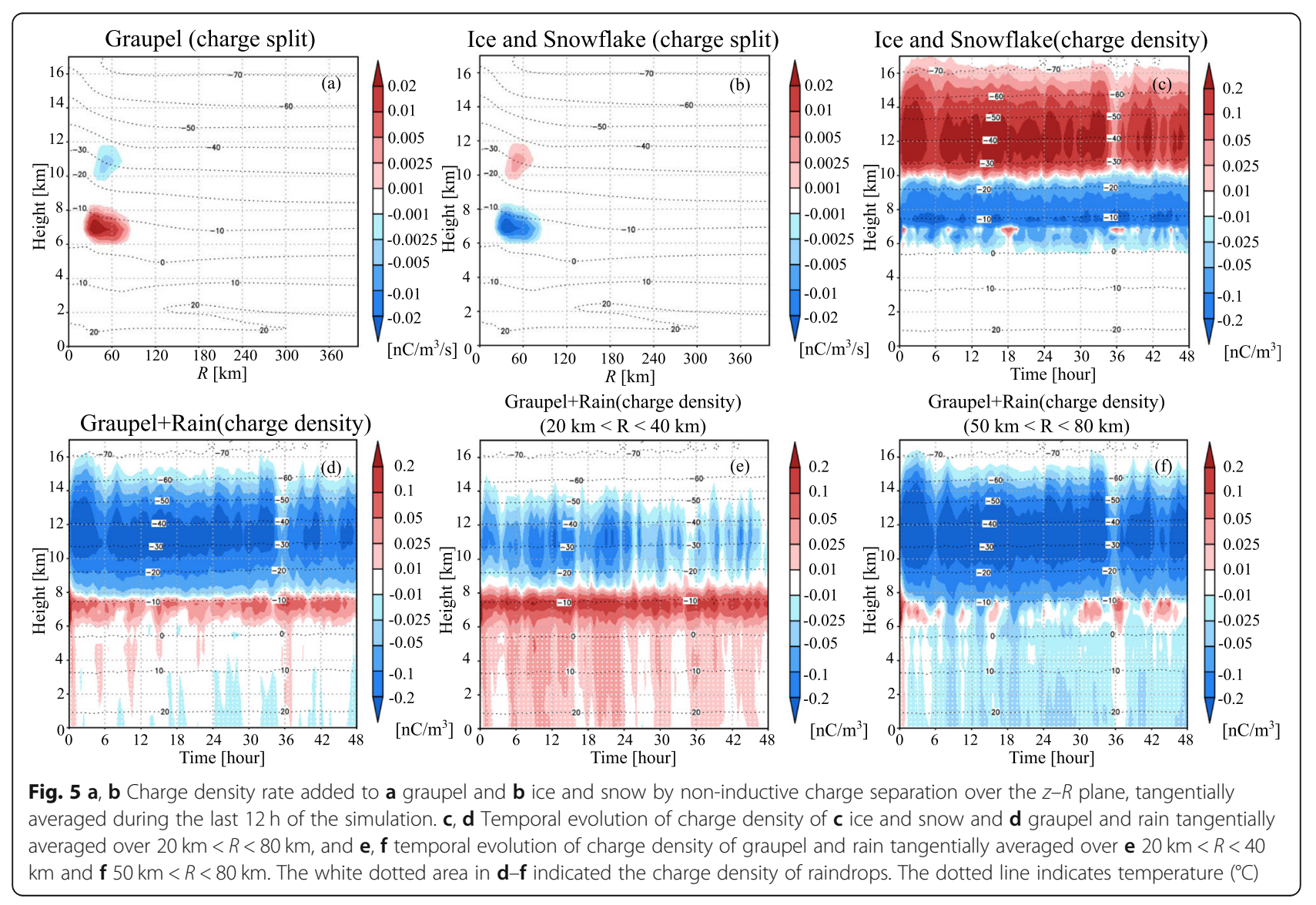


temperature at this layer is included in the blue shaded area of the LUT (Fig. 1). The positively charged snow and ice are carried upward and create positively charged anvil clouds above the height of $10 \mathrm{~km}$ (Figs. $4 \mathrm{~b}$ and 5c). Some of the negatively charged graupel falls down, while the rest is elevated by the upward velocity and distributed between the height of 9 and $16 \mathrm{~km}$ (Fig. 5d).

The relationships between charge density and hydrometeor type described above support the report of Fierro et al. (2007), which simulated a TC using a meteorological model coupled with a lightning model.

In addition to the tripole structure in the inner core region, we note the negative charge density originating from negatively charged raindrops (dash-dotted black line in Fig. 4b) seen between the radius range of 50 and $80 \mathrm{~km}$. The negatively charged raindrops are generated from the melting of negatively charged graupels, and the polarity exhibits a dipole structure from bottom to upper layer. The graupels originally obtain negative charge density above the height of $10 \mathrm{~km}$. The graupels are transported outside of the $\mathrm{TC}$ by the centrifugal force with falling to lower layer. As a result of the transport by the centrifugal force, the graupels are outside of eyewall region (i.e., between the radius range of 50 and $80 \mathrm{~km}$ ), when they fall to the height of $0{ }^{\circ} \mathrm{C}$ (Fig. $5 \mathrm{f}$ ).

The tripole pattern near the center and dipole pattern outside the center are similar to the schematic illustration of the vertical structure of charge density and hydrometeors of a squall line system derived from the videosonde observation in Figure 7 of Takahashi and Keenan (2004).

\section{Effect of aerosols on hydrometeors and charge density structure in a TC}

The successful simulation of the vertical structures of $q_{\text {hyd }}$ and charge density of the TC encouraged us to investigate the impact of aerosols on these structures. Figure 6 shows maximum wind velocity at the height level of $1 \mathrm{~km}$ with $N_{0}$ of $10 \mathrm{~cm}^{-3}, 100 \mathrm{~cm}^{-3}$ (control simulation), and $1000 \mathrm{~cm}^{-3}$ without the lightning model. The impact of aerosols on the strength of the TC is weak. This result is contrary to the reports of previous studies (e.g., Rosenfeld et al. 2012; Khain et al. 2008a), which suggested that a TC is weakened with increasing aerosol number concentrations. This inconsistency is explained by the difference in the structure of the TC in the previous studies compared to that in the present study. Based on the previous reports, an increase in aerosols suppresses precipitation in the outer rain band region and reduces the pressure gradient between the outer rain band region and center of the TC through the cold-pool dynamics and feedback. The change in pressure gradient weakens the TC. For the TC simulated in

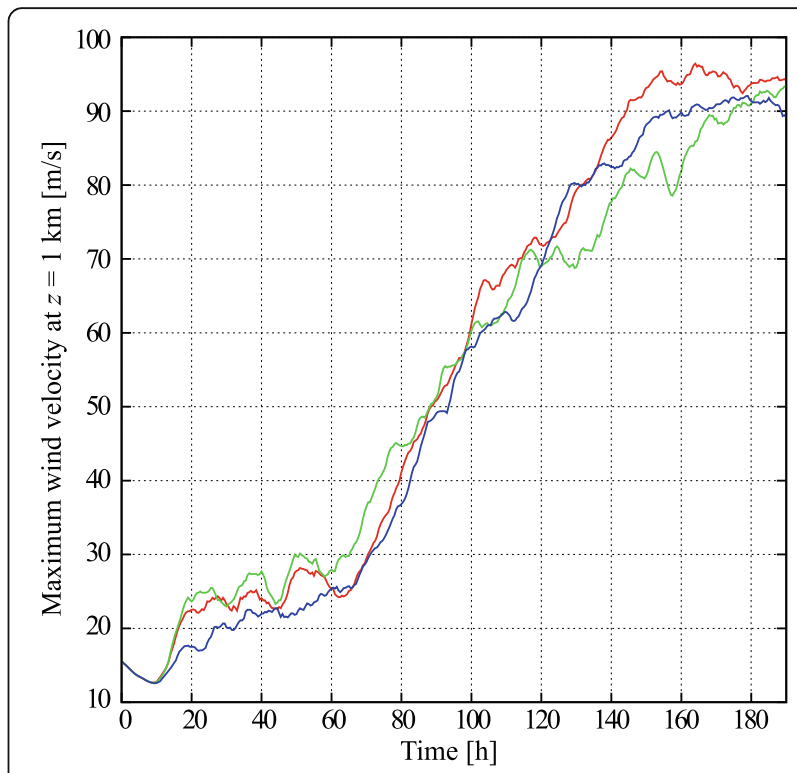

Fig. 6 Temporal evolution of maximum wind velocity at $z=1 \mathrm{~km}$ as $150 \mathrm{~min}(\mathrm{~min})$ moving averaged value with $N_{0}=10 \mathrm{~cm}^{-3}$ (green), $N_{0}=100 \mathrm{~cm}^{-3}$ (red), and $N_{0}=1000 \mathrm{~cm}^{-3}$ (blue)

this study, the outer rain band was not clear, and the cold-pool dynamics and feedback missed.

Figures $4 \mathrm{a}, 7 \mathrm{a}$, and $8 \mathrm{a}$ show the vertical distributions of the cloud water mixing ratio and cloud number concentration with $N_{0}$ of $10 \mathrm{~cm}^{-3}, 100 \mathrm{~cm}^{-3}$, and $1000 \mathrm{~cm}^{-3}$. In the inner core region, the $q_{\text {hyd }}$ below the melting level $(z=6 \mathrm{~km})$, mainly composed of liquid water particles, became large at $N_{0}$ of $10 \mathrm{~cm}^{-3}$. The $q_{\text {hyd }}$ decreased as the aerosol number concentration increased. By contrast, the $q_{\text {hyd }}$ above the melting level, which corresponds to mixed-phase clouds, became large as the aerosol concentration increased. The results can be interpreted using the cloud invigoration hypothesis, suggested by Rosenfeld et al. (2008) as follows.

In the pristine condition (when $N_{0}$ is $10 \mathrm{~cm}^{-3}$ ), size of hydrometeors around the cloud base tend to be larger than the control case, as demonstrated by the smaller number concentration of cloud droplets compared to the control case (solid black contour line, Fig. 7a). The large cloud droplets easily coalesce into large raindrops and rain out before reaching the melting level. As a result, the warm rain process dominates. The dominant warm rain process reduces the $q_{\text {hyd }}$ above the melting level in the pristine condition.

By contrast, in the polluted condition (when $N_{0}$ is $1000 \mathrm{~cm}^{-3}$ ), the size of cloud droplets is smaller due to $\mathrm{ACI}$, as demonstrated by the large number concentration of cloud droplets compared to the control case (solid black contour line, Fig. 8a). In this case, the coalescence is suppressed around the height of $7 \mathrm{~km}$, 

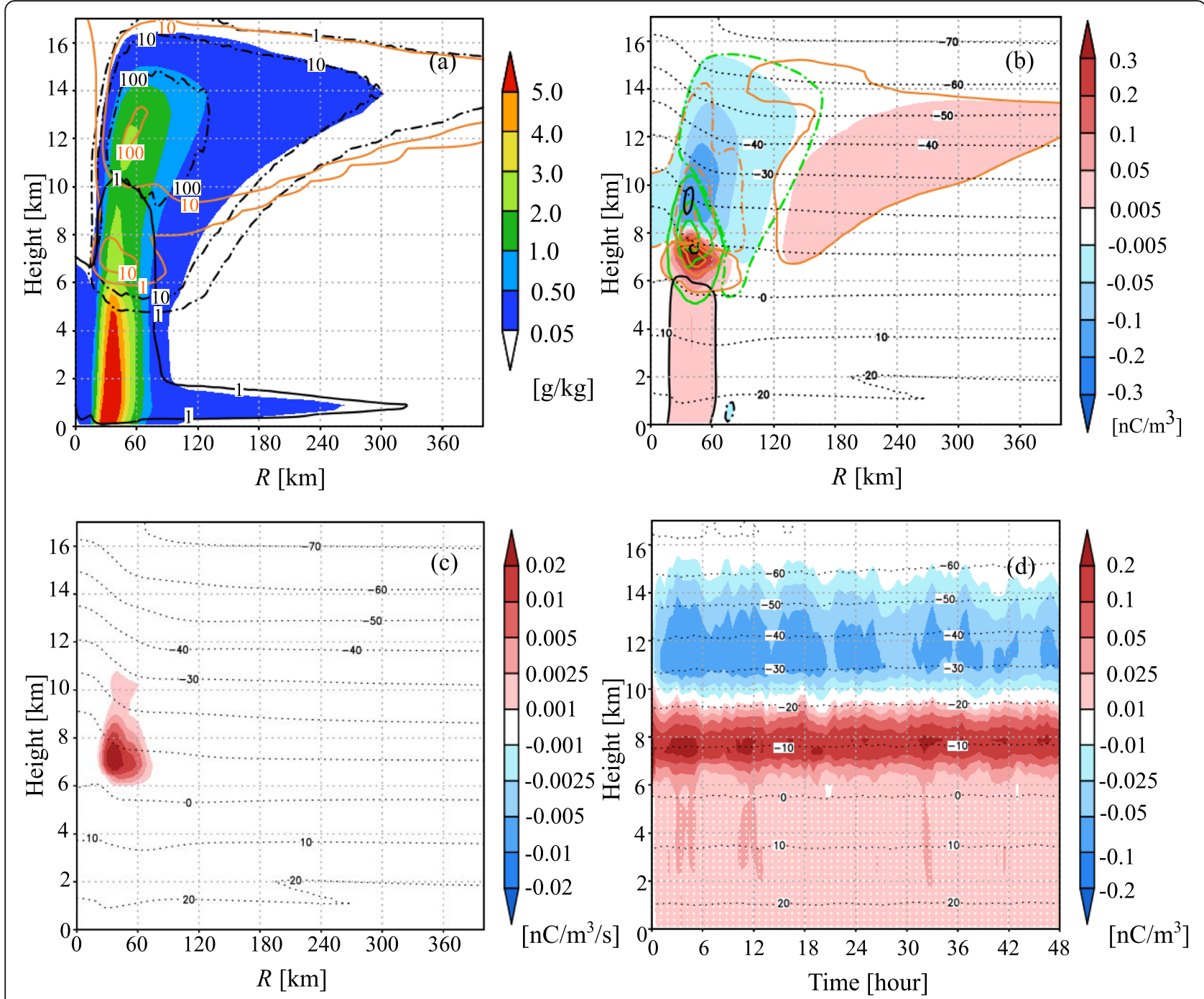

Fig. 7 a Number concentrations of water (black solid contour line; unit: $\mathrm{cm}^{-3}$ ), ice and snow (orange contour line; unit: $\mathrm{L}^{-1}$ ), and graupel (black dot-dashed line; unit: $\mathrm{L}^{-1}$ ), and $q_{\text {hyd }}$ (shaded area). $\mathbf{b}$ Charge density of hydrometeors (shaded area), cloud and rain (black contour line), ice and snow (orange contour line), and graupel (green contour line). c Charge density rate added to graupel by non-inductive charge separation over the $z-R$ plane simulated and $\mathbf{d}$ temporal evolution of the charge density of graupel tangentially averaged over $20 \mathrm{~km}<R<80 \mathrm{~km}$ with $N_{0}=10$ $\mathrm{cm}^{-3}$. The white dotted area in $\mathbf{d}$ indicated the charge density of raindrops. The dotted line in $\mathbf{b}$ - $\mathbf{d}$ indicates temperature $\left({ }^{\circ} \mathrm{C}\right)$. Solid and dashdotted contours in $\mathbf{b}$ show positive and negative charge charge densities, respectively. The contour lines in $\mathbf{b}$ show $0.01,0.1$, and $0.3 \mathrm{nC} \mathrm{m}^{-3}$, respectively. The variables were tangentially averaged during the last $12 \mathrm{~h}$ of the simulation

and rain generation is prohibited. As a result of the prohibition on raindrop formation, cloud droplets remain small and are easily carried above the melting level by the updraft in the eyewall region. In this case, ice-phase cloud particles become larger, as demonstrated by the large $q_{\text {hyd }}$ around the height of $11 \mathrm{~km}$ (Fig. 8a).

These impacts of aerosols on cloud structure largely affect the structure of charge density, as shown in Figs. $4 \mathrm{~b}, 7 \mathrm{~b}$, and $8 \mathrm{~b}$. Under the pristine condition (when $N_{0}$ is $10 \mathrm{~cm}^{-3}$; Fig. 7b), the positively charged anvil, which is simulated within the height above $12 \mathrm{~km}$ in the control case (Fig. 4b), is more obscure than in the control simulation (Fig. 7b). Additionally, the positive charge density composed of positively charged graupel and raindrops below the height of $8 \mathrm{~km}$ is clearer than in the control case (Fig. 7b, d). In contrast to the pristine condition, the negative charge density is distributed from the surface up to about the height of $10 \mathrm{~km}$, and the tripole structure is not seen under the polluted condition (when $N_{0}$ is $1000 \mathrm{~cm}^{-3}$; Fig. 8b).

The reason for the dependence of the charge density on aerosols can be examined from the distribution of the charge separation rate of graupel, as shown in Fig. 8c. The ice and snow particles are given the same charge density, as shown in Figs. 5b, 7c, and 8c, but opposite polarities. 

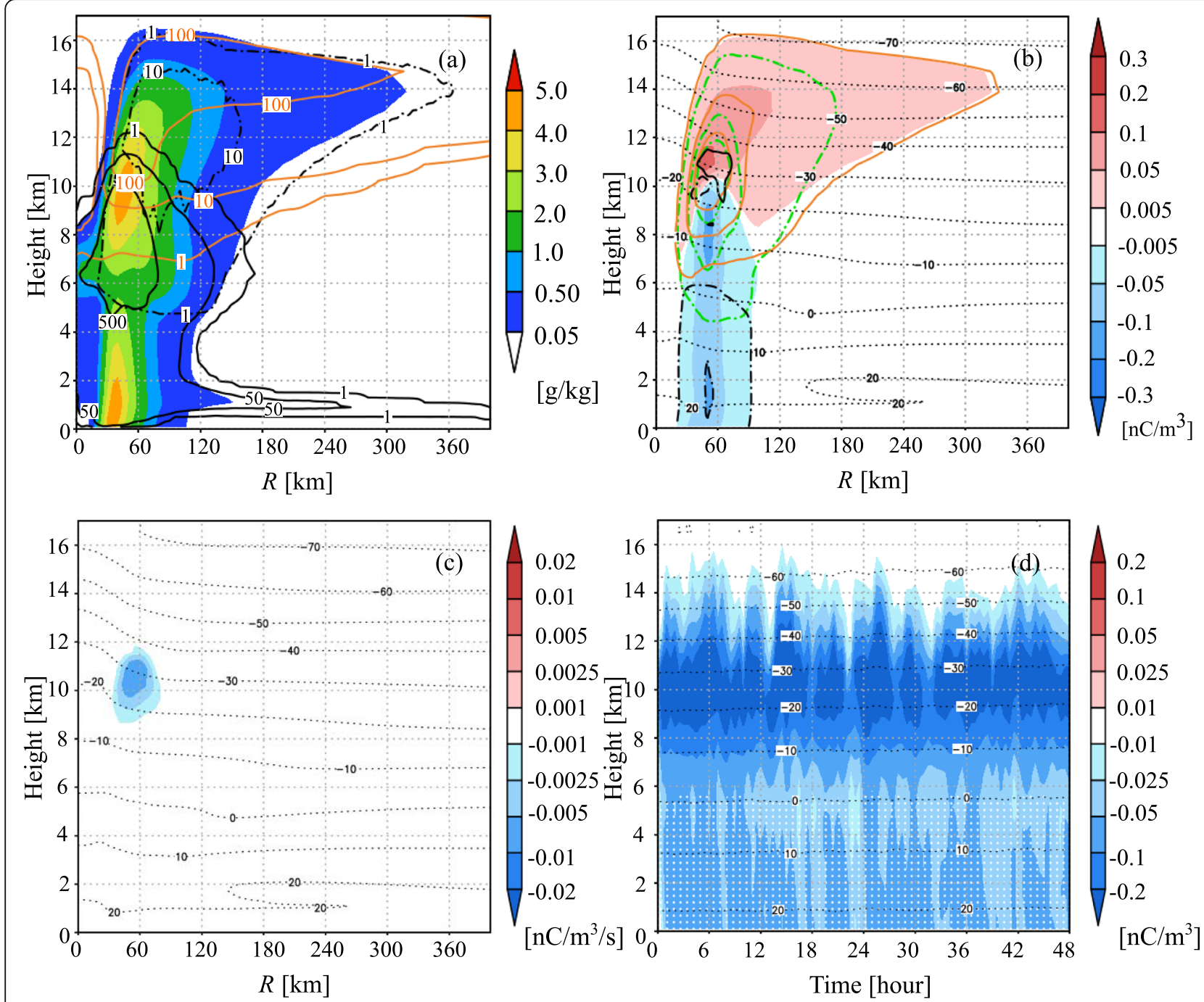

Fig. 8 a Number concentrations of water (black solid contour line; unit: $\mathrm{cm}^{-3}$ ), ice and snow (orange contour line; unit: $\mathrm{L}^{-1}$ ), and graupel (black dot-dashed line; unit: $\mathrm{L}^{-1}$ ), and qhyd (shaded area). b Charge density of hydrometeors (shaded area), cloud and rain (black contour line), ice and snow (orange contour line), and graupel (green contour line). c Charge density rate added to graupel by non-inductive charge separation over the z-R plane simulated and $\mathbf{d}$ temporal evolution of the charge density of graupel tangentially averaged over $20 \mathrm{~km}<\mathrm{R}<80 \mathrm{~km}$ with $\mathrm{N}_{0}=$ $1000 \mathrm{~cm}^{-3}$. The white dotted area in d indicated the charge density of raindrops. The dotted line in $\mathbf{b}-\mathbf{d}$ indicates temperature $\left({ }^{\circ} \mathrm{C}\right)$. Solid and dash-dotted contours in b show positive and negative charge charge densities, respectively. The contour lines in b show $0.01,0.1$, and $0.3 \mathrm{nC}$ $\mathrm{m}^{-3}$, respectively. The variables were tangentially averaged during the last $12 \mathrm{~h}$ of the simulation

The non-inductive charge separation around the height of $7 \mathrm{~km}$, by which graupel is positively charged, is clearly seen under the pristine condition (Fig. 7c). It gradually becomes unclear with increasing aerosol concentrations, and it is not seen under the polluted condition (when $N_{0}$ is $1000 \mathrm{~cm}^{-3}$; Fig. $8 \mathrm{c}$ ). In the pristine condition, the size of graupel generated around the height of $7 \mathrm{~km}$ is larger than in the control simulation due to ACI. In this case, the collision of graupel with ice and snow easily occurs. Therefore, the non-inductive charge separation rate is larger (Fig. 7c). The large charge separation results in the large positive charge density around the height of $7 \mathrm{~km}$ (Fig. 7b, d). In this case, the large-sized positively charged graupel easily falls down and melts into raindrops, resulting in the widely distributed positive charge density below about 8 $\mathrm{km}$ height (Fig. 7b, d). The negatively charged ice and snow generated by the collision with the graupel in this layer are not easily carried to the anvil layer due to the large size; therefore, the positively charged anvil is more obscure under the pristine condition (Fig. 7b) than in the control simulation (Fig. 4b), although the tripole structure is weakly seen.

By contrast, under the polluted condition, the noninductive charge separation around the height of $7 \mathrm{~km}$ is not clear (Fig. 8c). The unclear charge separation 
also originates from ACI described as follows. The size of the graupel is smaller than in the control case due to $\mathrm{ACI}$, and the collision of graupel with ice/snow at the height of $7 \mathrm{~km}$ is prohibited. This prohibition results in the small amount of non-inductive charge separation in the polluted case (Fig. 8c). Alternatively, the collision of graupel and ice/snow frequently occurs at the height around $11 \mathrm{~km}$ because the graupel gradually becomes large while rising up to the height of $11 \mathrm{~km}$, and graupel is negatively charged in this layer (Fig. 8b, d). The frequent collisions induce the large noninductive charge separation around the height of 11 $\mathrm{km}$. The negatively charged graupel originating from the charge separation falls down and melts into negatively charged raindrops (Fig. 8d). This results in the negative charge density from the surface to about the height of $12 \mathrm{~km}$. As a result of the processes shown above, the dipole structure of the charge density is seen in the polluted case.

In summary, the impact of aerosols is clear in the layer in which non-inductive charge separation mainly occurs. Due to the aerosol effect, the charge separation, which occurs about the height of $7 \mathrm{~km}$, is not clear in the polluted condition. The tripole structure becomes obscure, and the dipole structure is seen in the polluted condition.

\section{Effect of aerosols on the number of lightning flashes in a} TC

The large impact of aerosols on the charge density resulted in a large dependence of the number of flashes on the aerosol concentration, as shown in Fig. 9. The flash number is defined as the number that the neutralization

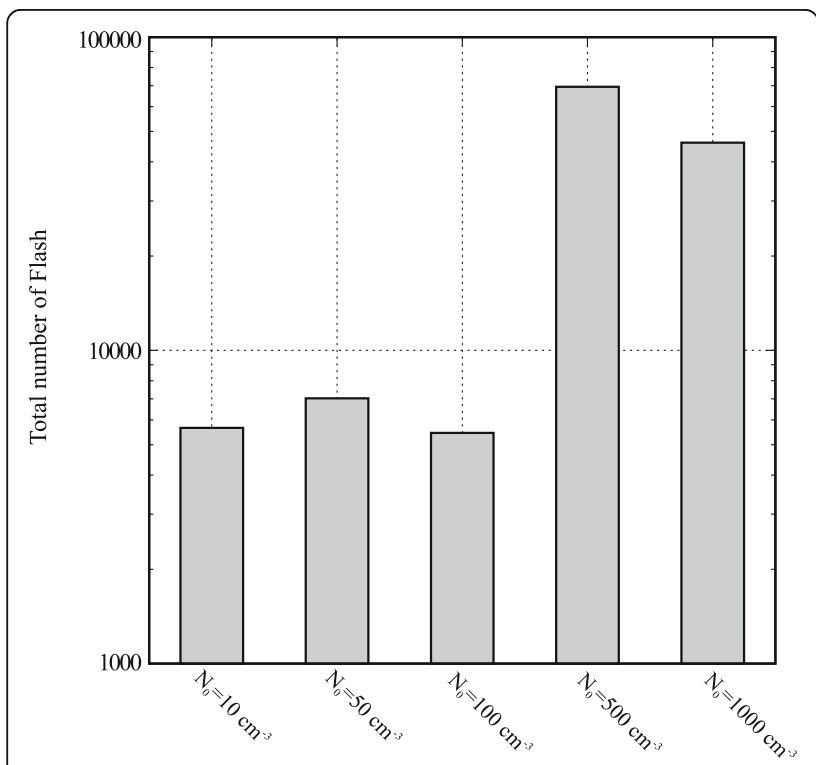

Fig. 9 Total number of lightning flashes accumulated during the last $36 \mathrm{~h}$ of the simulation with a parameter sweep of $N_{0}$ scheme is called, and it cannot be compared with the observed flash number. However, we can discuss the relative difference of the flash number. The flash number in pristine and control simulations was mostly the same regardless of the aerosol number concentration. Under the polluted condition (i.e., when $N_{0}$ is larger than $500 \mathrm{~cm}^{-3}$ ), the flash number was much larger than under the pristine condition. The dependence of the flash number on the aerosol number concentration originates from the vertical structure of the charge density. As described in the previous section, the tripole structure is seen in the control simulation and the pristine condition. The tripole structure in pristine condition is not clear with tangentially and temporally averaged charge density (Fig. 7b), but tripole structure is clearly seen in snapshot. By contrast, the vertical structure of charge density is a dipole in the polluted condition. The dipole structure tends to create a large $|\boldsymbol{E}|$ magnitude because $\boldsymbol{E}$ is calculated as the gradient of the Laplacian of the charge density (Eqs. (5) and (6)). The large $|\boldsymbol{E}|$ in the polluted condition results in frequent occurrences of $|\boldsymbol{E}|$ larger than $E_{\text {int }}$. As a result of the large $|\boldsymbol{E}|$, the flash number under the polluted condition is much larger than that under the pristine condition. The dipole structure is clear when $N_{0}$ is larger than $500 \mathrm{~cm}^{-3}$; therefore, the flash number becomes large when $N_{0}$ is larger than $500 \mathrm{~cm}^{-3}$.

These dependencies of the lightning frequency in TC inner core upon aerosols should be compared with the observation, but the dependency has not been observed due to the difficulty to isolate the aerosol effects from the observation. However, in view of the effect of the aerosol on the lightning, the contrast of lightning frequency over the ocean and the continent for convective clouds in tropical region gives some hints to imply the effect of aerosol on lightning with TCs. Over the continent, aerosol number concentration is larger than that over the ocean. Satellite observation using Tropical Rainfall Measuring Mission (TRMM) Lightning Imaging Sensor (LIS) data (Zipser et al. 2006) and using TRMM LIS and Optical Transient Detector (OTD) (Albrecht et al. 2016) reported the larger frequency of the flush over the continent than the ocean. In addition, an observational study reported the possibility of the positive correlation between the aerosol optical depth and flush number (Yuan et al. 2011). As well as these studies, the dependency of the aerosols on the lightning density simulated in this study is qualitatively similar to the results of the satellite observation using TRMM LIS data (Liu et al. 2012; Stolz et al. 2015). They conducted the statistical analyses using 9-year data of TRMM LIS measurement and reported that the total lightning density is larger with the larger aerosol number concentration. To understand the relationship between our results 
and the results of the satellite observation, we need to make a detailed comparison between modeling results and observation from satellite in the future.

\section{Conclusions}

In this study, the effects of aerosols on the charge distribution and number of lightning flashes in a TC were investigated by developing a lightning model and implementing it in SCALE. The lightning model predicts the charge density of the hydrometeors in each grid and considers the non-inductive charge separation (Takahashi 1978), the calculation of the electric field (solving the Poisson equation), and the charge neutralization (MacGorman et al. 2001; Fierro et al. 2013). Using SCALE coupled with the lightning model, the effect of aerosols on the charge distribution of a TC was simulated. The simulation results revealed that the effect of aerosols on the strength of the $\mathrm{TC}$ is small, but their impact on the charge distribution and number of flashes in the TC is large. In the pristine and moderate (control) conditions, the tripole structure, which has been reported by a number of previous studies, is clearly seen. By contrast, in the polluted condition, the positive charge density near the melting level $(z=6-8 \mathrm{~km})$ is obscure, and the vertical structure of the charge distribution is a dipole. The dipole structure originates from the suppression of non-inductive charge separation around the height of $7 \mathrm{~km}$ as a result of the suppression of the collisions between graupel and ice/snow. The flash number becomes large when the dipole structure occurs, that is, under the polluted condition.

In this study, we focused on the charge distribution and number of lightning flashes in an idealized TC simulation. Based on the relationship between the growth process of hydrometeors and charge density, the dipole stricture and large flash number that occur with large aerosol concentrations are possible in other types of cloud systems. A previous modeling study showed a dipole structure and large flash number under polluted conditions for squall line systems (Mansell and Ziegler 2013). To completely validate the dipole structure and understand the effect of aerosols on lightning frequency, a comparison between model-simulated and observed charge densities is necessary in the future.

We investigated the impact of aerosols on charge distribution and lightning in an idealized TC with no rain band in this study. Due to the unclear rain band, the impact of aerosols on the TC intensity and lightning over the outer rain band was small. Thus, we focused on the impact of aerosols on the inner core in this study. To obtain general knowledge of the impact of aerosols on TCs, we must conduct numerical simulations for TCs with rain bands and real TCs by nesting simulation in the future.

\section{Abbreviations}

ACl: Aerosol-cloud interaction; CCN: Cloud condensation nuclei; LUT: Lookup table; RI: Rapid intensification; SCALE: Scalable Computing for Advanced Library and Environment; TC: Tropical cyclone

\begin{abstract}
Acknowledgements
This research is partly supported by JSPS Grant-in-Aid for Scientific Research (C) (Proposal number: 17 K05659), JSPS KAKENHI Grant Number JP18H05872, RIKEN special post-doctoral fellow program (XXVII-008), Initiative on Promotion of Supercomputing for Young or Women Researchers, Information Technology Center, The University of Tokyo, and Research Field of Hokkaido Weather Forecast and Technology Development (Endowed by Hokkaido Weather Technology Center Co. Ltd.). SCALE library was developed by TeamSCALE of RIKEN Center for Computational Sciences (http://r-ccs-climate.riken. jp/scale/). Some of the figures were created by Grid Analysis and Display System (GrADS: Institute for Global Environment and Society (IGES) 1989).
\end{abstract}

\section{Authors' contributions}

YS proposed this study, developed and implemented the new lightning model, conducted all simulations, analyzed the results, and drafted the manuscript. YM constructed the experimental setup of the simulation and discussed about the analyses and results. HT discussed about the development of the lightning model and gave many useful comments for drafting the manuscript. All authors read and approved the final manuscript.

\section{Authors' information}

YS and YM have contributed to the development of SCALE library as a member of Team-SCALE of RIKEN, and both of them are visiting researcher of RIKEN. HT is a director of the Team-SCALE.

\section{Funding}

YS is partly supported by JSPS Grant-in-Aid for Scientific Research (C) (proposal number: 17 K05659), RIKEN special post-doctoral fellow program (XXVII008), and Initiative on Promotion of Supercomputing for Young or Women Researchers, Information Technology Center, The University of Tokyo. YM is partly supported by JSPS KAKENHI grant number JP18H05872.

\section{Availability of data and materials}

The source code of SCALE library without the lightning model is published from the website of SCALE (http://r-ccs-climate.riken.jp/scale/). The source code of the lightning component and data is available upon request from the corresponding author (YS).

\section{Competing interests}

The authors declare that they have no competing interests.

\section{Author details}

${ }^{1}$ Department of Earth and Planetary Sciences, Faculty of Science, Hokkaido University, Kita 10, Nishi 8, Kita-ku, Sapporo, Hokkaido 060-0810, Japan. ${ }^{2}$ Computational Climate Science Research Team, RIKEN Center for Computational Science, 7-1-26 Minatojima-Minami-machi, Chuo-ku, Kobe, Hyogo 650-0047, Japan. ${ }^{3}$ Faculty of Environment and Information Studies, Keio University, 5322, Endo, Fujisawa, Kanagawa 252-0882, Japan.

${ }^{4}$ Mathematical Climatology Laboratory, RIKEN Cluster for Pioneering Research, 2-1 Hirosawa, Wako, Saitama 351-0198, Japan.

Received: 20 May 2019 Accepted: 24 September 2019

Published online: 26 October 2019

\section{References}

Abarca SF, Corbosiero KL, Vollaro D (2011) The world wide lightning location network and convective activity in tropical cyclones. Mon Wea Rev 139:175191. https://doi.org/10.1175/2010MWR3383.1

Albrecht BA (1989) Aerosols, cloud microphysics, and fractional cloudiness. Science 245:1227-1230. https://doi.org/10.1126/science.245.4923.1227

Albrecht Rl, Goodman SJ, Buechler DE, Blakeslee RJ, Christian HJ (2016) Where are the lightning hotspots on Earth? Bull Am Meteorol Soc 97:2051-2068. https://doi.org/10.1175/BAMS-D-14-00193.1

Barthe C, Chong M, Pinty J-P, Bovalo C, Escobar J (2012) CELLS v1.0: updated and parallelized version of an electrical scheme to simulate multiple electrified 
clouds and flashes over large domains. Geosci Model Dev 5:167-184. https:// doi.org/10.5194/gmd-5-167-2012

Barthe C, Molinié G, Pinty J-P (2005) Description and first results of an explicit electrical scheme in a 3D cloud resolving model. Atmos Res 76:95-113. https://doi.org/10.1016/j.atmosres.2004.11.021

Brook M, Nakano M, Krehbiel P, Takeuti T (1982) The electrical structure of the Hokuriku winter thunderstorms. J Geophys Res 87:1207. https://doi.org/10. 1029/JC087iC02p01207

Cecil DJ, Zipser EJ (2002) Reflectivity, ice scattering, and lightning characteristics of hurricane eyewalls and rainbands. Part II: intercomparison of observations. Mon Wea Rev 130:785-801. https://doi.org/10.1175/1520-0493(2002)130< 0785:RISALC $>2.0 . C O ; 2$

Cecil DJ, Zipser EJ, Nesbitt SW (2002) Reflectivity, ice scattering, and lightning characteristics of hurricane eyewalls and rainbands. Part l: quantitative description. Mon Wea Rev 130:769-784. https://doi.org/10.1175/15200493(2002)130<0769:RISALC>2.0.CO;2

Cotton WR, Zhang H, McFarquhar GM, Saleeby SM (2007) Should we consider polluting hurricanes to reduce their intensity? J. Wea Modif 39:70-73

DeMaria M, DeMaria RT, Knaff JA, Molenar D (2012) Tropical cyclone lightning and rapid intensity change. Mon Wea Rev 140:1828-1842. https://doi.org/10. 1175/MWR-D-11-00236.1

Fierro AO, Leslie L, Mansell E, Straka J, MacGorman D, Ziegler C (2007) A highresolution simulation of microphysics and electrification in an idealized hurricane-like vortex. Meteorog Atmos Phys 98:13-33. https://doi.org/10. 1007/s00703-006-0237-0

Fierro AO, Mansell ER (2017) Electrification and lightning in idealized simulations of a hurricane-like vortex subject to wind shear and sea surface temperature cooling. J Atmos Sci 74:2023-2041. https://doi.org/ 10.1175/JAS-D-16-0270.1

Fierro AO, Mansell ER (2018) Relationships between electrification and stormscale properties based on idealized simulations of an intensifying hurricane-like vortex. J Atmos Sci 75:657-674. https://doi.org/10.1175/JASD-17-0202.1

Fierro AO, Mansell ER, Macgorman DR, Ziegler CL (2013) The implementation of an explicit charging and discharge lightning scheme within the WRF-ARW model: benchmark simulations of a continental squall line, a tropical cyclone, and a winter storm. Mon Wea Rev 141:2390-2415. https://doi.org/10.1175/ MWR-D-12-00278.1

Fierro AO, Mansell ER, Ziegler CL, MacGorman DR (2015) Explicitly simulated electrification and lightning within a tropical cyclone based on the environment of hurricane Isaac (2012). J Atmos Sci 72:4167-4193. https://doi. org/10.1175/JAS-D-14-0374.1

Franklin CN, Holland GJ, May PT (2005) Sensitivity of tropical cyclone rainbands to ice-phase microphysics. Mon Wea Rev 133:2473-2493. https://doi.org/10. 1175/MWR2989.1

Hayashi S (2006) Numerical simulation of electrical space charge density and lightning by using a 3-dimensional cloud-resolving model. SOLA 2:124-127. https://doi.org/10.2151/sola.2006-032

Iguchi T, Nakajima T, Khain AP, Saito K, Takemura T, Suzuki K (2008) Modeling the influence of aerosols on cloud microphysical properties in the east Asia region using a mesoscale model coupled with a bin-based cloud microphysics scheme. J Geophys Res 113:D14215. https://doi.org/10.1029/2007JD009774

Institute for Global Environment and Society (IGES) (1989) Grid Analysis and Display System (GrADS). http://www.iges.org/grads/grads.html. Accessed 1 May 2014

Jacobson EA, Krider EP (1976) Electrostatic field changes produced by Florida lightning. J Atmos Sci 33:103-117. https://doi.org/10.1175/15200469(1976)033<0103:EFCPBF>2.0.CO;2

Jiang JH, Su H, Massie ST, Colarco PR, Schoeberl MR, Platnick S (2009) Aerosol-CO relationship and aerosol effect on ice cloud particle size: analyses from Aura microwave limb sounder and aqua moderate resolution imaging spectroradiometer observations. J Geophys Res 114:D20207. https://doi.org/ 10.1029/2009JD012421

Khain A, Cohen N, Lynn B, Pokrovsky A (2008a) Possible aerosol effects on lightning activity and structure of hurricanes. J Atmos Sci 65:3652-3677. https://doi.org/10.1175/2008JAS2678.1

Khain AP, BenMoshe N, Pokrovsky A (2008b) Factors determining the impact of aerosols on surface precipitation from clouds: an attempt at classification. J Atmos Sci 65:1721-1748. https://doi.org/10.1175/2007JAS2515.1

Khain AP, Rosenfeld D, Pokrovsky A (2001) Simulating convective clouds with sustained supercooled liquid water down to $-37.5^{\circ} \mathrm{C}$ using a spectral microphysics model. Geophys Res Lett 28:3887-3890. https:/doi.org/10.1029/ 2000GL012662

Khain AP, Sednev IL (1995) Simulation of hydrometeor size spectra evolution by water-water, ice-water and ice-ice interactions. Atmos Res 36:107-138. https://doi.org/10.1016/0169-8095(94)00030-H

Krehbiel PR, Brook M, McCrory RA (1979) An analysis of the charge structure of lightning discharges to ground. J Geophys Res 84:2432. https://doi.org/10. 1029/JC084iC05p02432

Lindsey DT, Fromm M (2008) Evidence of the cloud lifetime effect from wildfireinduced thunderstorms. Geophys Res Lett 35:2-6. https://doi.org/10.1029/ 2008GL035680

Liu C, Cecil DJ, Zipser EJ, Kronfeld K, Robertson R (2012) Relationships between lightning flash rates and radar reflectivity vertical structures in thunderstorms over the tropics and subtropics. J Geophys Res 117. https://doi.org/10.1029/ 2011JD017123

MacGorman DR, Straka JM, Ziegler CL (2001) A lightning parameterization for numerical cloud models. J Appl Meteorol 40:459-478. https://doi.org/10. 1175/1520-0450(2001)040<0459:ALPFNC >2.0.CO;2

Mansell ER, MacGorman DR, Ziegler CL, Straka JM (2005) Charge structure and lightning sensitivity in a simulated multicell thunderstorm. J Geophys Res 110:D12101. https://doi.org/10.1029/2004JD005287

Mansell ER, Ziegler CL (2013) Aerosol effects on simulated storm electrification and precipitation in a two-moment bulk microphysics model. J Atmos Sci 70: 2032-2050. https://doi.org/10.1175/JAS-D-12-0264.1

Mansell ER, Ziegler CL, Bruning EC (2010) Simulated electrification of a small thunderstorm with two-moment bulk microphysics. J Atmos Sci 67:171-194. https://doi.org/10.1175/2009JAS2965.1

Miyamoto Y, Takemi T (2013) A transition mechanism for the spontaneous axisymmetric intensification of tropical cyclones. J Atmos Sci 70:112-129. https://doi.org/10.1175/JAS-D-11-0285.1

Molinari J, Moore P, Idone V (1999) Convective structure of hurricanes as revealed by lightning locations. Mon Wea Rev 127:520-534. https://doi.org/10.1175/ 1520-0493(1999)127<0520:CSOHAR>2.0.CO;2

Nakanishi M, Niino H (2006) An improved Mellor-Yamada level-3 model: its numerical stability and application to a regional prediction of advection fog. Boundary-Layer Meteorol 119:397-407. https://doi.org/10.1007/s10546-0059030-8

Nishizawa S, Yashiro H, Sato Y, Miyamoto Y, Tomita H (2015) Influence of grid aspect ratio on planetary boundary layer turbulence in large-eddy simulations. Geosci Model Dev 8:3393-3419. https://doi.org/10.5194/gmd-83393-2015

Price C, Asfur M, Yair Y (2009) Maximum hurricane intensity preceded by increase in lightning frequency. Nat Geosci 2:329-332. https://doi.org/10.1038/ ngeo477

Pruppacher HR, Klett JD (2010) Microphysics of clouds and precipitation, 2nd edn. Springer Netherlands, p 955. https://doi.org/10.1007/978-0-306-48100-0

Rosenfeld D, Khain A, Lynn B, Woodley WL (2007) Simulation of hurricane response to suppression of warm rain by sub-micron aerosols. Atmos Chem Phys 7:3411-3424. https://doi.org/10.5194/acp-7-3411-2007

Rosenfeld D, Lohmann U, Raga GB, O'Dowd CD, Kulmala M, Fuzzi S, Reissell A, Andreae MO (2008) Flood or drought: how do aerosols affect precipitation? Science 321:1309-1313. https://doi.org/10.1126/science.1160606

Rosenfeld D, Woodley WL, Khain A, Cotton WR, Carrió G, Ginis I, Golden JH (2012) Aerosol effects on microstructure and intensity of tropical cyclones. Bull Am Meteorol Soc 93:987-1001. https://doi.org/10.1175/ BAMS-D-11-00147.1

Rotunno R, Emanuel KA (1987) An air-sea interaction theory for tropical cyclones. Part II: evolutionary study using a nonhydrostatic axisymmetric numerical model. J Atmos Sci 44:542-561. https://doi.org/10.1175/1520-0469(1987)044< 0542:AAITFT>2.0.CO;2

Sato Y, Nishizawa S, Yashiro H, Miyamoto Y, Kajikawa Y, Tomita H (2015) Impacts of cloud microphysics on trade wind cumulus: which cloud microphysics processes contribute to the diversity in a large eddy simulation? Prog Earth Planet Sci 2(23). https://doi.org/10.1186/s40645-015-0053-6

Seiki T, Nakajima T (2014) Aerosol effects of the condensation process on a convective cloud simulation. J Atmos Sci 71:833-853. https://doi.org/10.1175/ JAS-D-12-0195.1

Sherwood SC (2002) Aerosols and ice particle size in tropical cumulonimbus. J Clim 15:1051-1063. https://doi.org/10.1175/1520-0442(2002)015<1051:AAIPSI>2.0.CO;2

Shi Z, Tan YB, Tang HQ, Sun J, Yang Y, Peng L, Guo XY (2015) Aerosol effect on the land-ocean contrast in thunderstorm electrification and lightning 
frequency. Atmos Res 164-165:131-141. https://doi.org/10.1016/j.atmosres. 2015.05.006

Stolz DC, Rutledge SA, Pierce JR (2015) Simultaneous influences of thermodynamics and aerosols on deep convection and lightning in the tropics. J Geophys Res 120:6207-6231. https://doi.org/10.1002/2014JD023033

Suzuki K, Nakajima T, Nakajima TY, Khain AP (2010) A study of microphysical mechanisms for correlation patterns between droplet radius and optical thickness of warm clouds with a spectral bin microphysics cloud model. J Atmos Sci 67:1126-1141. https://doi.org/10.1175/2009JAS3283.1

Takahashi T (1978) Riming electrification as a charge generation mechanism in thunderstorms. J Atmos Sci 35:1536-1548. https://doi.org/10.1175/15200469(1978)035<1536:REAACG >2.0.CO;2

Takahashi T (1984) Thunderstorm electrification-a numerical study. J Atmos Sci 41:2541-2558. https://doi.org/10.1175/1520-0469(1984)041<2541: TENS>2.0.CO;2

Takahashi T, Kawano T (1998) Numerical sensitivity study of rainband precipitation and evolution. J Atmos Sci 55:57-87. https://doi.org/10.1175/ 1520-0469(1998)055<0057:NSSORP>2.0.CO;2

Takahashi T, Keenan TD (2004) Hydrometeor mass, number, and space charge distribution in a "Hector" squall line. J Geophys Res 109:D16208. https://doi. org/10.1029/2004JD004667

Takahashi T, Shimura K (2004) Tropical rain characteristics and microphysics in a three-dimensional cloud model. J Atmos Sci 61:2817-2845. https://doi.org/ 10.1175/JAS-3294.1

Tao W-K, Chen J-P, Li Z, Wang C, Zhang C (2012) Impact of aerosols on convective clouds and precipitation. Rev Geophys 50:2011RG000369. https:// doi.org/10.1029/2011RG000369

Tao W-K, Li X, Khain A, Matsui T, Lang S, Simpson J (2007) Role of atmospheric aerosol concentration on deep convective precipitation: cloud-resolving model simulations. J Geophys Res 112:D24S18. https://doi.org/10.1029/ 2007JD008728

Tomita H (2008) New microphysical schemes with five and six categories by diagnostic generation of cloud ice. J Meteorol Soc Japan 86A:121-142. https://doi.org/10.2151/jmsj.86A.121

Twomey S (1959) The nuclei of natural cloud formation part II: the supersaturation in natural clouds and the variation of cloud droplet concentration. Geofis Pura e Appl 43:243-249. https://doi.org/10.1007/ BF01993560

Twomey S (1977) The influence of pollution on the shortwave albedo of clouds. J Atmos Sci 34:1149-1152. https://doi.org/10.1175/1520-0469(1977)034<1149: TIOPOT>2.0.CO;2

Uno I, Cai X-M, Steyn DG, Emori S (1995) A simple extension of the Louis method for rough surface layer modelling. Boundary-Layer Meteorol 76:395-409. https://doi.org/10.1007/BF00709241

van der Vorst HA (1992) Bi-CGSTAB: a fast and smoothly converging variant of BiCG for the solution of nonsymmetric linear systems. SIAM I Sci Stat Comput 13:631-644. https://doi.org/10.1137/0913035

Yuan T, Remer LA, Pickering KE, Yu H (2011) Observational evidence of aerosol enhancement of lightning activity and convective invigoration. Geophys Res Lett 38. https://doi.org/10.1029/2010GL046052

Ziegler CL, MacGorman DR, Dye JE, Ray PS (1991) A model evaluation of noninductive graupel-ice charging in the early electrification of a mountain thunderstorm. J Geophys Res 96:12833-12855. https://doi.org/10.1029/ 91JD01246

Zipser EJ, Cecil DJ, Liu C, Nesbitt SW, Yorty DP (2006) Where are the most intense thunderstorms on Earth? Bull Am Meteorol Soc 87:1057-1072. https://doi. org/10.1175/BAMS-87-8-1057

\section{Publisher's Note}

Springer Nature remains neutral with regard to jurisdictional claims in published maps and institutional affiliations.

\section{Submit your manuscript to a SpringerOpen ${ }^{\circ}$ journal and benefit from:}

- Convenient online submission

- Rigorous peer review

- Open access: articles freely available online

- High visibility within the field

- Retaining the copyright to your article

Submit your next manuscript at $\boldsymbol{\nabla}$ springeropen.com 